important idea of twisting, which suggests not only torsion but the final stage in the production of rope: the twisting of the tough flaxen fibres into cord.

Attempts to relate siege-engines to Pylos and Messene are clearly misguided. It has proved more fruitful to pursue the area's connexion with rope, an approach to the line which is signalled in the text.*

St Anne's College, Oxford

RACHEL WILLIAMS

- I should like to thank Professor R. G. M. Nisbet, who encouraged me to write this and provided helpful criticism; also Dr N. M. Horsfall for valuable comments on reading a later draft.

\title{
Microfilms of manuscripts
}

Microfilms or photographs of manuscripts can be of use to other scholars when they have served their original purpose, but even large collections have a habit of disappearing. May we urge anyone in Great Britain who possesses or obtains a seproduction of any classical manuscript to inform the Librarian of the Institute of Classical Studies, 31-34 Gordon Square, London WC1H OPY? The only information needed is (1) shelfmark of manuscript; (2) contents in brief; (3) likely destination after use.

THE EDITORS 